\title{
Notions of shock and Attention in Tik Tok videos
}

\author{
Keywords \\ Attention, Platform Culture, Shock, Social Network, Tik Tok.
}

This work seeks to understand how and if the entertainment experience obtained by watching videos on the Tik Tok social platform that uses editing and design tools, such as distortion filters for physical appearance and voice, is also an immersive experience that causes a shock to the user as understood by Walter Benjamin (2010) when this communicational subject is crossed by a sensation of the modern and that has, as a consequence, the disintegration of the aura in the experience of shock. According to Rouanet (1990) "the psychic instance in charge of capturing and absorbing the shock starts to dominate over the instances in charge of storing memory impressions". In this case awareness has the function of "serving as protection against stimuli, sublimating impacts, maturing the fright into anguish or fun, so as not to succumb to amazement" (PEIXOTO, 1983) and can be linked to the production of content of fast circulation and absorption, made exclusively for social networks and platforms such as Tik Tok. Platforms that work with such design are also guided by the hands of users with content creation to shock an audience immersed in what is called Snack Culture (SCOLARI, 2020). As for a culture that develops a sensorial audiovisual content format, these contents provoke a sensory effect, a brief and ephemeral experience within a project that can be understood as artistic and created in a dynamic between playful and entertainment. The sensorial effect of these contents offers a unique and unprecedented experience, typical of an avant-garde work of art. In the 'contemporary arcades' of the Internet, videos from both Tik Tok and other platforms - with similar features - have similar tools created daily increasing the number of accesses, seeking to retain the media user and seem to attempt to lead the user to an immersive experience in an Attention Economy system as described by Jonathan Crary (2015) as something that "dissolve the separation between the personal and the professional, between entertainment and information, displaced by a compulsory functionality of communication inherently and inescapably 24/7." Altogether with these ideas is the view of Simon Reynolds (2010) that popular culture has become a remix or rereading of something done before, based on any type of information available. Therefore, from this point of view, the reappropriation becomes infinite - something you see in Tik Tok videos. This text is built applied to the communicational practice of the use of platforms and is an attempt to understand the contemporary media paths that are outlined with the platform of culture. The platforms, a communication event in itself, raise questions about a new circulation of goods and gestures by communicational subjects who act on this frequency. It is a work that positions itself in the face of the contemporary urgency of the online life, its fast transformations and society's pursuits in a time that requires critical thinking about the moment we live in. to account for the moment in which we live. 